2006-01-01

\title{
Childhood Sexual Abuse Among University Students in Tanzania
}

\author{
Denis McCrann \\ Technological University Dublin \\ Kevin Lalor \\ Technological University Dublin, kevin.lalor@tudublin.ie \\ Joviter K. Katabaro \\ University of Dar-es-Salaam
}

Follow this and additional works at: https://arrow.tudublin.ie/aaschsslarts

Part of the Child Psychology Commons, and the Sociology Commons

\section{Recommended Citation}

McCrann, D., Lalor, K., Katabaro, J. Childhood Sexual Abuse Among University Students in Tanzania, Child Abuse and Neglect, Vol. 30, Issue 12, 2006,pp.1343-1351. doi:10.1016/j.chiabu.2006.05.009

This Article is brought to you for free and open access by the Social Sciences at ARROW@TU Dublin. It has been accepted for inclusion in Articles by an authorized administrator of ARROW@TU Dublin. For more information, please contact arrow.admin@tudublin.ie, aisling.coyne@tudublin.ie,gerard.connolly@tudublin.ie.

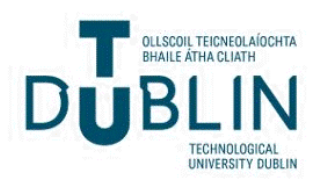




\section{CHILD SEXUAL ABUSE AMONG UNIVERSITY STUDENTS IN TANZANIA}

\section{INTRODUCTION}

Child sexual abuse is a serious breach of basic human rights and is responsible for numerous adverse sequelae (Roberts, O’Connor, Dunn, \& Golding, 2004; Steel, Sanna, Hammond, Whipple, \& Cross 2004); its wide-spread presence in both developing and developed countries is well documented (Finkelhor, 1994; Back, Jackson, Fitzgerald, Shaffer, Salstrom, \& Osman, 2003; McGee, Garavan, de Barra, Byrne \& Conroy, 2003). Gorey and Leslie (1997) reported a $22.3 \%$ prevalence rate of child sexual abuse among women and $8.5 \%$ prevalence rate among men from an aggregate of 16 studies. A review of about 30 studies of community and convenience samples found widely varying estimates of the prevalence of child sexual abuse ranging from $3 \%$ to $30 \%$ for males and from $6 \%$ to $62 \%$ for females (Fergusson \& Mullen, 1999). Child sexual abuse appears to be a universal phenomenon; wherever it has been sought out it has been found (Finkelhor, 1994). The latter study reported that most perpetrators were male and that one third of sexual abuse was intra-familial.

Although studies of child sexual abuse conducted in developing countries are emerging, the process is slow and sporadic. Child sexual abuse has been identified in Brazil (Farinatti, Fonseca, Dondonis, \& Brugger, 1990), India (Segal \& Ashtekar, 1994, Patel \& Andrew, 2001), El Salvador (Barthauer \& Leventhal, 1999), Palestine (Haj-Yahi \& Tamish, 2001) and the Republic of South Africa (Jaffe \& Roux, 1988; Levett, 1989; 
Haffejee, 1991; Collings, 1995; Madu \& Peltzer, 2001). In sub-Sahara Africa (SSA), peer-reviewed research into child sexual abuse is limited and largely confined to the Republic of South Africa (Lalor, 2004a). With a few notable exceptions (Okeahialam, 1984; Lema, 1997; Meursing, Vos, Coutinho, Moyo, Mpofu, Oneko, Mundy, Dube, Mahlangu, \& Sibindi, 1995; Shumba, 2004) research conducted outside of South Africa is scarce.

Rates of child sexual abuse vary in African studies, thus corresponding to studies in developed countries. Variations are likely to be due to methodological issues, which occur throughout child sexual abuse research (Leventhal, 1998; Fergusson \& Mullen, 1999). The rate of abuse varies according to the definition used; for example, when 'touched sexually by force' was used as a question, 5.2\% of participants were deemed sexually abused (Madu, 2001) compared to $26.3 \%$ when 'unwanted genital fondling' (Collings, 1997) was used. Despite the discrepancies in reporting across studies, the existence of child sexual abuse as a serious social problem in Africa cannot be denied. King, Flisherb, Noubarya, Reecec, Maraisb, \& Lombardd (2004) sampled 2,946 secondary students from Cape Town and reported rates for attempted rape of $8.4 \%$, while $5.8 \%$ had been actually raped. The available studies confirm the high prevalence of intrafamilial abuse and the fact that many perpetrators are known or closely related to their victims can be overshadowed where there is emphasis on commercial forms of child sexual abuse, such as prostitution (see Lalor, 2004a). 


\section{Causes of child sexual abuse}

Lalor (2004a) categorises three widespread explanations for child sexual abuse in subSaharan Africa: rapid social change; HIV cure and avoidance strategy and the patriarchial nature of society. The "virgin cleansing myth" is linked inextricably to the latter two explanations, that is, the belief that intercourse with a virgin can cure disease or otherwise bring good fortune. Ecker (1994) was informed in Keffi, Nigeria that "old men are advised to have sexual contact with virgin girls in order to cure sexually transmitted diseases" (p. 20). In the Republic of South Africa this belief has been blamed as a cause for the recent spate of infant rapes (Bowley \& Pitcher 2002a; Bowley, \& Pitcher, 2002b; Richter, 2003). Jewkes, Matubatuba, Metsing Ngcobo, Makaota, Mbhalati, Frohlich, Wood, Kabi, Ncube, Nduna, Jama, Moumakoe, \& Raletsemo (2000) report from a sexual health workshop with 293 participants that $32.7 \%$ of the participants believed sex with a virgin could cure HIV. Surprisingly, after 14 sessions, $20 \%$ of the participants still held that view. The Tanzanian Media Women's Association (TAMWA, 1998) noted that sixty members of the Tanzanian parliament believed witch doctors, or traditional healers, were responsible for encouraging men to defile and sexually abuse children in the pursuit of health and wealth.

Poverty is also recognised as an important factor fuelling child sexual abuse. It forces young people to engage in transactional sex or the "sugar daddy/mammy phenomenon" whereby young women/men gain financial support from older men/women in return for sexual services rendered (Ecker, 1994). Often the women/men are very young and the 
experiences abusive. For many girls and women such early sexual behaviour is motivated by the receipt of money or other small gifts. Caldwell et al. (1989), drawing on the work of Little (1973), believe "an understanding of the traditional African viewpoint, which regarded sex as a worldly activity like work or eating and drinking, is essential for an understanding of the dimensions of African sexual networking" (p. 203). The age at which sexual relations become acceptable is much more difficult to gauge. Silberschmidt (2001) noted the "sexual networking" performed by women in Tanzania and Kenya and believed it was "the result of the breakdown of traditional norms and regulations surrounding sexual behaviour" (p. 666). A study by Dunkle, Jewkes, Brown, Gray, McIntryre and Harlow (2004) found that $21.1 \%$ of 1395 pregnant women in South African clinics "reported having ever had sex with a non-primary male partner in exchange for material goods or money" (p. 1581). In an interview study examining the sexual activities of fifty-one adolescent girls who had just had abortions in Dar es Salaam, Silberschmidt and Rasch (2001) discovered that the majority of girls had "sugar daddy" partners or mshikaji wa muda who provided small "luxuries" in exchange for their sexual services. "It is believed that sexual services are commodities that should be paid for" (p. 1821). Some of the girls had more than one "sugar daddy" at a time. The Kenya Demographic and Health Survey reports that 15\% of adolescent girls who have ever had sexual intercourse (it's important to note that a majority, 56\%, have not ever had sexual intercourse) have done so in exchange for money, gifts or favours in the previous 12 months (National Council for Population and Development (NCPD), Central Bureau of Statistics (CBS) (Office of the Vice President and Ministry of Planning and National Development) [Kenya], and Macro International (MI), 1999). Writing of Tanzania, 
Fuglesang (1997) recognises the practical aspect of the presence of "sugar daddies"; "economic gain has to be acknowledged as having an impact on the courtship behaviour of adolescent girls" (p. 1246). Silverschmidt (2001) argues that due to the economic upheaval of the last few decades African men have become dis-empowered and use sex to reassert their masculinity. They see extra-marital sex as necessary to their identity and it "is a legitimate way for men to enhance self-esteem and masculinity" (p. 667). The attempt to avoid catching HIV is also embroiled in this complex matter. What of "sugar mammies" as a potential source of child sexual abuse among young males? It has received little attention in research to date but may become more prominent as gender roles evolve and African women become less and less reliant on men for support. Silberschmidt (2001) notes "Successful businesswomen in Dar es Salaam are even said to pay younger men for sex” (p. 665). In a study investigating reports of male sexual abuse by male and female perpetrators in two Zimbabwean schools, Shumba (2004) discovered just one case out of five involved women as perpetrators; he attributes this to gross underreporting of female abusers.

\section{Studies investigating child sexual abuse in Tanzania}

In Tanzania, the paucity of published studies dealing with child sexual abuse is noted in a review by Lalor (2004b). It reveals clearly the scattered nature of research and identifies the need to gather data to dispel mistruths and myths. Lalor's review draws attention to the fact that most studies investigating child sexual abuse in Tanzania use margalised samples such as street children (Rajani and Kudrati, 1996) and hospital samples (Asser, 
Hizza, Mrema \& Hamudu, 1996). The latter study provides evidence of serious forms of child sexual abuse. One hundred and two victims of alleged rape were treated at the Muhimbili hospital; of these 71 per cent were under the age of 14 and in 61 per cent of cases the assailant was known to the victim. Lugalla and Mbwambo (1999) examined street children and street life and corroborate the findings of Rajani and Kudrati (1996) in that they highlight the active sex life the young children lead. The children had various partners, with anal sex being common. The use of condoms was non-existent and the transactional nature of sex was a cause for concern in an environment rife with HIV.

Lalor (2004b) notes that a number of studies of Tanzanian youth have been conducted; however, in most cases, the subject of child sexual abuse has been excluded from these surveys (UNICEF, 1999; ILO, 2001). A UNICEF study (2003) attempted to collect nationally all available data on child sexual abuse and estimated that one out of three females and one out of five males had been victims of child sexual abuse and that girls were twice as likely to be victims of sexual victimisation than boys throughout childhood but eight times more likely during adolescence. The report details information from Mount Meru hospital in northern Tanzania for the year 2000 in which 20 boys had been victims of child sexual abuse. Information from Dar es Salaam police reveal that during the period 2000-2002, there were 293 cases of rape, 68 cases of indecent assault and 57 cases of sodomy. Information from the Kigoma police records for the period JanuarySeptember 2002 reveal a total of 20 cases of child sexual abuse; 14 labelled sexual abuse; 3 rape and 3 sodomy cases. In the period 2000-2002 data from the Morogoro Regional Court show 98 cases of child rape and 21 cases of sodomy. These figures are likely to be 
gross underestimations but they highlight the existence of child sexual abuse and denote a real need for further research especially in light of the HIV pandemic. It is unclear how Unicef arrived at their estimates of one third of females and one fifth of males nationwide experiencing child sexual abuse based on these data. They conclude:

"Generally, there is a need to carry out a comprehensive study on child abuse so as to accentuate the emerging forms and circumstances of child abuse and different conceptions of child abuse by different communities" (UNICEF, 2003, p. 87).

This echoes a UNICEF (Tanzania) call for research made in 1998 to

“develop a properly researched information base on sexual abuse and its incidence in the Tanzanian context, in institutions, schools and homes" (UNICEF, 1999, p. 357).

Purposes of the present study

The present study aims to explore the prevalence rate of child sexual abuse among a sample of college students at a University in Tanzania. Preferably, a randomised representative sample of the general population should be surveyed. However, because this is one of the pioneer studies of child sexual abuse in Tanzania, a university sample was deemed more accessible. A similar research approach was adopted by Tang (2002) 
in which child sexual abuse was first looked at among Chinese college students. University students are seen as more open, willing to talk about sexual matters more freely, and are less affected by temporal and recall bias (Finkelhor, Hotaling, \& Yllo, 1989: Tang, Yik, Cheung, Choi, \& Au, 1996). The study will also investigate the nature of the abuse; assessing the age of the victim, the duration of the abuse, type of perpetrators involved, the amount of force or persuasion involved, as well as the perceived causes of child sexual abuse. 


\section{METHOD}

Operational definition of child sexual abuse adopted by this investigation

Kempe and Kempe (1978) defined child sexual abuse as:

"The involvement of dependent, developmentally immature children and adolescents in sexual activities which they do not fully comprehend, are unable to give informed consent to and that violate social taboos of family roles" (p. 60).

Broadly, this definition was employed for the present study. In addition, the following criteria were set:

1. It was stipulated that the sexual behaviour experienced by the respondent had to have taken place while the person was under the age of eighteen years. This position was taken to ensure congruence with the United Nation Convention on the Rights of the Child (1989), of which Tanzania is a signatory.

2. It was also stipulated on the questionnaire that the sexual incidents experienced be unwanted.

3. An age differential of 5 years had to exist between the victim of the unwanted sexual experience and the perpetrator. This age differential has been used to ensure that a power differential existed. This ensured that abusive or unwanted same-age relationships were not deemed child sexual abuse. 


\section{Participants}

Undergraduates from a University in Tanzania took part in the study. Four hundred and eighty seven students, consisting of 282 males and 204 females completed the questionnaire. One participant failed to specify a gender. The students came from varying geographical and ethnic backgrounds. The age of the group ranged from 20 to 53 years, the mean age being 29 and the median 27 years. Fifty separate ethnic groups completed the survey. The majority came from the Chagga and Haya tribes. Sixty-one per cent of the sample were single, $37 \%$ married and less than $1 \%$ either divorced, separated or widowed.

\section{Materials}

A questionnaire modelled closely on that of Lisak and Luster (1994) was used. Some minor amendments were made to account for the Tanzanian cultural context. The questionnaire asked a comprehensive set of specific questions to secure maximum clarity on the issue. It consisted of 24 questions, which can be divided into demographic and opinion questions, and early sexual experiences questions. The cover page explained the purpose of the questionnaire. It defined "a child" in line with the UNCRC, that is, "a person under 18 years of age" and also stated that the sexual experience encountered be "uncomfortable and unwanted". An assurance of confidentiality and privacy was given. The questionnaire concluded by thanking the participants for their time and honesty and also by directing the students to the relevant counselling services, should they wish. 
Ethical clearance for the project was granted by the Research Ethics Committee of the Dublin Institute of Technology. The Tanzanian Commission for Science and Technology also granted the research permit. The University in question allowed the researchers permission to conduct the research. Participants gave informed consent.

\section{Procedure}

In Tanzania the questionnaire was rewritten at the chosen University to gauge its sensitivity to cultural issues. Minimal changes regarding wording that might not be understandable to the population was suggested. Appropriate changes were made before piloting began.

Piloting was carried out on 40 second-year undergraduate students. The students were encouraged to ask questions if they had any difficulty with the wording or if they needed clarification on any point. Students appeared to comprehend the material without much difficulty.

The third stage involved distributing the anonymous, self-administered questionnaire. It was dispensed to two separate undergraduate classes; 299 first year students and 188 third year students from a mixed range of degree areas. It was carried out in large lecture halls, where a certain degree of privacy was available. Students were informed that there was no requirement to participate in the study. All the questionnaires were attempted but 
many were only partially answered. It took the participants approximately 30 minutes to complete the questionnaire.

Six interviews (one male and five female) were carried out with victims of child sexual abuse. The interviews sought to confirm information provided in the questionnaire and to glean additional information about the nature of child sexual abuse. A focus group with two non-victims (one male and one female) of child sexual abuse took place to gauge common views among students.

\section{Limitations}

The researchers acknowledge that there are limitations present in the study. Caution must be exercised when interpreting the results. Like most retrospective studies of child sexual abuse the possibility for a recall bias skewing the results existed. The study did not have external verification for the information provided. This was beyond the means of the study. The sample used was non-random. All respondents attempted the questionnaire (although some provided more information than others). The response rate varied from question to question. This may be an artefact of the questionnaire or may be related to the information that was been asked of the participants. The questionnaire was not in the first language of the participants. It was hoped comprehension issues were resolved in piloting although the possibility that some participants failed to understand some questions remains, in spite of being students on courses taught through English. 


\section{RESULTS}

\section{Child sexual abuse experience}

Respondents were asked to indicate whether they had experienced an unwanted sexual experience before the age of 18 . To constitute child sexual abuse the perpetrator had to be five or more years older than the respondent. A total of 135 respondents (27.7\%) reported having experienced at least one type of abusive sexual experience before the age of 18 (many respondents had more than one experience; this information is revealed in the individual analysis of abuse). Table 1 illustrates the breakdown and severity of each type of abuse for males and females. As evident from table 1, unwanted fondling and kissing were the most common form of child sexual abuse $\left(X^{2}=6.16, d f=1, p<0.05\right.$ and $\mathrm{X}^{2}=15.10, \mathrm{df}=1, \mathrm{p}<0.001$ respectively). Unwanted masturbation and flashing were experienced by $8 \%$ of the respondents, while $6 \%$ reported unwanted oral sex. Unwanted sexual intercourse was high, especially for woman (11.2\%). The corresponding figure for men (8.8\%) relates to experiences young males ( $<18$ years) had with women at least five years their senior. It indicates that many early adolescent boys were involved in unwanted sexual relationships with older women.

Table 1 About Here 
Age of victim when abuse occurred

The average age of a victim of child sexual abuse is 13.6 years and 15 is the age at which most abuse occurs (Table 2). The mean age at which males are abused (13.5 years) is slightly lower age than the age for females (13.8 years). The average age for unwanted sexual intercourse is 12.6 years for males and 14.2 years for females. Victims experiencing unwanted exposure to another's genitals ("flashing") were the youngest (12.7 years). Pre-pubertal sexual abuse is evident in table 3; it accounts for $10.2 \%$ of all abuse recorded. It is important to note from this table that pre-pubertal boys were found to have experienced more sexual abuse than girls and that just over one per cent of the sample experienced unwanted sexual intercourse before age thirteen.

Table 2 and 3 About Here

\section{Duration of abuse}

As is evident from table 4, the child sexual abuse took place over a broad timeline from days through to years in some cases. Sexual abuse most commonly took place over a period of days; this amounted to 129 episodes of sexual abuse. The numbers of episodes of sexual abuse that occurred over weeks, months and years are lower but all three are considerable. Overall there were 46 episodes of abuse that took place over a period 'weeks', 56 over 'months' and 35 over 'years' . This figure for prolonged abuse (years) is high. Consequently these respondents are more likely to be susceptible to the adverse effects of child sexual abuse. There was a high missing figure for this question; that is 
participants who admitted experiencing some form of child sexual abuse but did not report its duration. Also it is important to remember that some participants reported the abuse occurring over more than one timeframe.

Table 4 About Here

\section{Perpetrators}

Respondents identified fifteen perpetrators. Unfortunately the two most common perpetrators mentioned were left unnamed; the respondents simply put 'man' or 'woman'. It cannot be assumed that these perpetrators were unknown; the respondents may have been protecting their identities. It is interesting to note that fathers or mothers were mentioned by none of the respondents. This is a highly unlikely scenario. It is more likely that sexual abuse at the hands of parents is hidden in the "unspecified males and females' response. As can be seen from tables 5 and 6, which examined the type of perpetrators involved for unwanted kissing and sexual intercourse, there is a high proportion of female perpetrators of child sexual abuse; this goes against most research findings, which highlight the preponderance of male perpetrators. Multiple perpetrators were mentioned seven times for unwanted kissing but they were not mentioned regarding unwanted sexual intercourse. The perpetrators present a large mix but many of them are known by the respondents (for example, friend, teacher, lover, aunt, uncle and neighbour). None of the respondents reported being abused by strangers; although some of the "unspecified male" and "unspecified female" responses may include strangers. It is important to note that a small number of women reported they had sexual intercourse 
with other women. This may signify a lack of understanding on the part of the participant or a different understanding of the term that was used by the researcher.

\section{Tables 5 and 6 About Here}

\section{Amount of force or persuasion involved in the child sexual abuse}

It is evident from tables 7 and 8 that there was considerable force and persuasion involved in the abusive experiences reported by the respondents. The figures reported are for specific episodes of abuse that occurred (sometimes the victim failed to respond for every episode). "Betrayal of trust" and "physical force" was the most frequently cited form of force or persuasion experienced by males and females respectively. Twenty-five per cent of males and 16 per cent of females who responded to the question reported the reason they had partaken in the early sexual experience was because of "bribes or enticements". The high figure relating to bribes and enticements suggests that a form of "transactional abuse" took place among the present sample. Often participants gave multiple responses for the type of force/persuasion involved. Males gave this response nine times while females reported it 18 times.

Tables 7 and 8 About Here 


\section{Perceived causes of child sexual abuse}

Respondents had clear ideas about what caused child sexual abuse and reported nine potential causes (Table 9). The most prominent causes mentioned were poverty and superstition which amounted to $63.4 \%$ of all reasons given. Poverty increases the vulnerability of young people to older sexual predators offering payment or financial support of some kind. Superstition was also much cited, related to beliefs perpetuated by witchdoctors about the powerful and cleansing nature of the virgin labia. Lack of education was mentioned by $15.7 \%$ of the sample, while HIV prevention strategy, substance abuse and modern influences accounted for $6.2,6.1$ and 6 per cent respectively. Biology was cited as an explanation by $1.6 \%$ of respondents.

Table 9 About here 


\section{DISCUSSION}

The present study investigated the incidence of unwanted sexual experiences before the age of eighteen with a person five years older in a sample of university students in Tanzania. It provides strong support for the existence of a level of child sexual abuse on par with rates reported in developed countries (or even higher). In retrospective studies of child sexual abuse in other countries average rates of child sexual abuse have been 22.3\% for females and $8.5 \%$ for males (Gorey and Leslie, 1997). The present study found that $31 \%$ of females and $25 \%$ of males had experienced some incident of child sexual abuse.

The most common forms of abuse noted were the least severe (in terms of adverse sequelae) - fondling and kissing ( $18.3 \%$ \& $12.9 \%$ respectively). However, the rates for the more severe forms of child sexual abuse were high in themselves. Unwanted masturbation was experienced by eight per cent, oral sex by 5.9 per cent, "flashing" by 7.8 per cent, anal intercourse by 2.5 per cent and sexual intercourse by 8.6 per cent. All forms of abuse were experienced by more females than males with the exception of anal intercourse, which was experienced by 4.6 per cent of males compared to 2.2 per cent of females. Unwanted sexual intercourse was experienced by 8.8 per cent of females and by 8.6 per cent of males. The figures recorded in this study are at the higher end of estimates for more severe forms of child sexual abuse (Finkelhor, Hotaling, Lewis, \& Smith, 1990; McGee et al, 2003; King et al. 2004). It is important to note that unwanted sexual intercourse reported by males refers to young men who have experienced 
unwanted sexual intercourse as a minor with women five years their senior. While not explicitly mentioned by participants it is possible many of the males had transactional sex with women for material gain - the "sugar mammy" phenomenon (Silberschmidt, 2001). In a focus group discussion with a male and a female student who had not experienced child sexual abuse, it emerged that it was not an uncommon experience for young males to have older "sugar mammies" in the very same way young girls use older men for material gain.

Average age at which abuse occurred was 13.6 years, although the average age for unwanted sexual intercourse was younger at 13.3 years. This is slightly different to previous research that suggests most child sexual abuse occurs pre-puberty (Finkelhor et al., 1990). A possible reason for this finding may be that a higher proportion of participants in this study had an unwanted sexual experience for material gain as opposed to being forced and that this occurred after the age of 12 . This conclusion is further supported by the high number of participants (25\% of males and $16 \%$ of females) admitting that bribes and enticements were involved in the unwanted sexual experience. However, it is important to note that female victims in the present study reported physical force as the primary determining factor in their abusive experiences (although bribes and enticements was mentioned frequently). Dunkle et al. (2004) report similar findings of transactional sex among women in Soweto, South Africa; they also reported the link between transactional sex and physical force. Transactional sex as a means of survival has long been reported in sub-Saharan Africa (Caldwell et al. 1989; Silberschmidt, 2001). However, approximately 10 per cent of the present sample had been sexually abused 
before or at the age of 12 , so it is dangerous to attribute poverty and transactional sex as the only reason behind the sexual abuse of the sample.

Abuse took place over a number of days or weeks in most cases but there are many instances of victimisation that took place over months and years. A number of child sexual abuse experiences were reported to have continued over a period of years, which is a cause for alarm. The behavioural outcome of child sexual abuse is strongly linked to the duration and frequency of the abuse (Steel et al, 2004); therefore, this finding is a cause for concern.

Research effort has recently focused on identifying the problem of child sexual abuse in developing countries and, in so doing; few studies have examined the consequences of abuse in specific cultural contexts (Collings, 1995; Collings, 1997; Meursing et al, 1998; Haj-Yahi \& Tamish, 2001). This needs to be addressed in sub-Saharan Africa in light of the different conceptualisations of sexuality (Caldwell et al., 1989) that exist. The perception of sexual abuse by the victims is also worth attention. Madu and Peltzer (2001) found that many victims of child sexual abuse (86.7\%) perceived themselves as not being sexually abused as children. It has previously been suggested that the outcome of an early sexual experience is greatly mediated by how the person perceives such experiences and is dependent "on how events are perceived, appraised and processed" (Williams, 1993, p. 46). It should be noted that conceptions and misconceptions about sexual abuse is a function of cultural factors, specifically the socialisation process children go through and how they are brought up. Socialisation is the process by which 
we learn the ways of a given society or social group so that we can function within it (Elkin \& Handel, 1978). Has Madu and Peltzer's sample been socialised to accept aggressive forceful sexual behaviour?

The perpetrators involved for the most part were unidentified male and females. The preponderance of female perpetrators was notable (110 out of 262 identified perpetrators were female) given that perpetrators are usually male (Finkelhor, 1994). It was surprising that none of the participants mentioned a parent or a sibling as being the abuser. This is contrary to previous findings which implicates close family members (Jaffe \& Roux, 1988; Collings, 1997). It is likely that the participants were protecting their family from possible repercussions or that the incest taboo is strong in this sample.

The perceived causes of child sexual abuse were manifold but poverty and superstition were mentioned most by the participants. Poverty partly explains the presence of transactional sex in Tanzanian society (even amongst the better off such as University students). The open, less puritan nature of African sexual life may also be an important factor. "The evidence is that Africans neither placed aspects of sexual behaviour at the centre of their moral and social systems nor sanctified chastity" (Caldwell et al., 1989, p. 194). The connection between child sexual abuse and superstition may be explained by the "virgin-cleansing myth", which was revealed by many of the participants as a perceived cause for child sexual abuse. Many participants mentioned the magical powers associated with having sexual contact with a virgin such as making a person wealthy. Closely linked to the virgin myth was "HIV avoidance strategy" as a cause for child sexual abuse, which was cited by over six per cent of the participants. That is, younger 
sexual partners are thought less likely to have HIV/Aids. Modern influences and biological urges were also mentioned. These findings concur with the three broad explanations for child sexual abuse noted by Lalor (2004a): rapid social change, STD/HIV avoidance strategy and male dominated nature of society.

\section{Implications}

The findings of this study suggest that child sexual abuse exists in Tanzania at similar levels to those reported throughout the world and that much of this abuse of the young is a product of a need for economic support and survival. If the basic needs of children continue to be neglected this form of "economic sexual exploitation" will continue.

The results also suggest that child sexual abuse as a form of HIV avoidance strategy or as a way of increasing one's wealth/health may exist. This needs further research.

The existence of child sexual abuse for pre-pubertal children was 10 per cent. This may rule out "transactional abuse" and points to the form of child sexual abuse usually reported. The absence of any incestuous experiences being explicitly mentioned by victims suggests the incest taboo is strong in Tanzania. 


\section{Summary and conclusions}

In summary, the findings of the current study indicate that child sexual abuse exists in this sample of Tanzanians to a similar degree as the rest of the world. Females suffer more abuse than men although the rate of abuse for males in this study is high. A level of "transactional abuse" was identified in this study whereby young adolescents received bribes and enticements for the sexual favours provided. Most perpetrators were unidentified but there were a lot of female perpetrators. Many perpetrators were known to the victims. The main perceived causes of child sexual abuse were poverty, superstition, lack of education, HIV avoidance strategies, substance abuse and "modern influences". 


\section{REFERENCES}

Asser, I., Hizza, E. C., Mrema, J. C., \& Hamudu, N. A. (1996). Rape and child abuse: a public health problem in Dar es Salaam. Presented at Tanzania Women Lawyers’ Association, The British Council, Dar es Salaam, September 12.

Back, S. E., Jackson, J. L., Fitzgerald, M., Shaffer, A., Salstrom, S., \& Osman, M. M. (2003). Child sexual and physical abuse among college students in Singapore and the United States. Child Abuse and Neglect, 27, 1259-1275.

Barthauer, L. M., \& Leventhal, J. M. (1999). Prevalence and effects of child sexual abuse in a poor, rural community in El Salvador: a retrospective study of women after 12 years of civil war. Child Abuse \& Neglect, 23(11), 1117-1126.

Bowley, D. M. \& Pitcher, G. J. (2002a). Infant rape in South Africa. Lancet, 359, 274275.

Bowley, D. M. \& Pitcher, G. J. (2002b). Motivation behind infant rape in South Africa. The Lancet, 359, 1352.

Caldwell, J., Caldwell, P., \& Quiggin, P. (1989). The social context of AIDS in subSaharan Africa. Population and Development Review, 15, 185-234.

Collings, S. J. (1995). The long-term effects of contact and noncontact forms of child sexual abuse in a sample of university men. Child Abuse \& Neglect, 19(1), 1-6.

Collings, S. J. (1997). Child sexual abuse in a sample of South African women students: Prevalence, characteristics, and long-term effects. South African Journal of Psychology, 27(1), 37-42. 
Dunkle, K. L., Jewkes, R. K., Brown, H. C., Gray, G. E., McIntryre, J. A., Harlow, S. D. (2004). Transactional sex among women in Soweto, South Africa: prevalence, risk factors and association with HIV infection. Social Science \& Medicine, 59, 1581-1592.

Ecker, N. (1994). Culture and sexual scripts out of Africa: A North American Trainer's View of Taboos, Tradition, Trouble and Truth. Siecus Report, 22(2), 16-22.

Elkin, F. \& Handel, G. (1978). The child and society: the process of socialization. New York: Random House.

Farinatti, F. A. S., Fonseca, N. M., Dondonis, M., \& Brugger, E. (1990). Child abuse and neglect in a developing country. Child Abuse \& Neglect, 14, 133-134.

Fergusson, D. M. \& Mullen, P. E. (1999). Child sexual abuse: an evidence based perspective. Thousand oaks: Sage.

Finkelhor, D. (1994). The international epidemiology of child sexual abuse. Child Abuse and Neglect, 18, 409-417.

Finkelhor, D., Hotaling, G. T., \& Yllo, K. (1989). Stopping family violence: research priorities for the coming decade. Newbury Park, CA: Sage.

Finkelhor, D., Hotaling, G., Lewis, A., Smith, C. (1990). Sexual abuse in a national survey of adult men and women: prevalence, characteristics, and risk factors. Child Abuse \& Neglect, 14(1), 19-28.

Fuglesang, M. (1997). Lessons for life - past and present modes of sexuality education in Tanzanian society. Social Science \& Medicine, 44(8), 1245-1254. 
Gorey, K. M \& Leslie, D. R. (1997). The prevalence of child sexual abuse: Integrative review adjustment for potential response and measurement biases. Child Abuse \& Neglect, 21(4), 391-398.

Haffejee, I.E. (1991). Sexual abuse of Indian (Asian) children in South Africa: first report in a community undergoing cultural change. Child Abuse and Neglect, 15, 147-151.

Haj-Yahi, M. M. Tamish, S. (2001). The rates of child sexual abuse and its psychological consequences as revealed by a study among Palestinian university students. Child Abuse and Neglect, 25, 1303-27.

International Labour Organisation (ILO)/International Programme for the Elimination of Child Labour. (2001). Tanzania: Children in prostitution, a rapid assessment. Geneva: ILO.

Jaffe, A.M. \& Roux, P. (1988). Sexual abuse of children - a hospital based study. South African Medical Journal, 74, 65-67.

Jewkes, R. L., Matubatuba, C., Metsing, D., Ngcobo, E., Makaota, F., Mbhalati, Frohlich, J., Wood, K., Kabi, K., Ncube, L., Nduna, Jama, N., Moumakoe, P., \& Raletsemo, S. (2000). Stepping Stones: Feedback from the field. http://www.actionaid.org/stratshope/ssjewkes.html (accessed May 30, 2004).

Jewkes, R. K, Vundule, C., Maforah, F., \& Jordaan, E. (2001). Relationship dynamics and teenage pregnancy in South Africa. Social Science \& Medicine, 52(5), $733-$ 744.

Kempe, R. S. \& Kempe, C. H. (1978). Child Abuse. London: Fontana/Open Books. 
King, G. A., Flisherb, A. J., Noubarya, F. B., Reecec, R., Maraisb, A \& Lombardd, C. (2004). Substance abuse and behavioral correlates of sexual assault among South African adolescents. Child Abuse and Neglect, 28(6), 685-698.

Lalor, K. (2004a). Child sexual abuse in sub-Saharan Africa: a literature review. Child Abuse and Neglect, 28(4) 439-460.

Lalor, K. (2004b). Child sexual abuse in Tanzania and Kenya. Child Abuse \& Neglect, 28(8), 833-844.

Leventhal, M. J. (1998). Epidemiology of sexual abuse of children: old problems, new directions. Child Abuse \& Neglect, 22(6), 481-491.

Levett, A. (1989). A study of childhood sexual abuse among South African university women students. South African Journal of Psychology, 19(3), 122-129.

Lisak, D. \& Luster, L. (1994). Educational, occupational, and relationship histories of men who were sexually and/or physically abused as children. Journal of Traumatic Stress, 7, 507-523.

Little, K. (1973). African Women in Towns: An Aspect of Africa's Social Revolution. Cambridge: Cambridge University Press.

Lugalla, J.L. \& Mbwambo, J.K. (1999). Street children and street life in urban Tanzania: The culture of surviving and its implications for children's health. International Journal of Urban and Regional Research, 23(2), 329-344.

Madu, S. N. (2001). The prevalence and patterns of childhood sexual abuse and victimperpetrator relationships among a sample of university students. South African Journal of Psychology, 31(4), 32-37. 
Madu, S. N. \& Peltzer, K (2001). Prevalence and patterns of childhood sexual abuse and victim-perpetrator relationships among secondary school student in the northern province. Archives of Sexual Behaviour, 30(3), 311-321.

McGee, H., Garavan, R., de Barra, M., Byrne, J. \& Conroy, R. (2002). The SAVI Report: Sexual abuse and violence in Ireland - a national study of Irish experiences, beliefs and attitudes concerning sexual violence. Dublin: The Liffey Press \& Dublin Rape Crisis Centre.

Meursing, K., Vos, T., Coutinho, O., Moyo, M., Mpofu, S., Oneko, O., Mundy, V., Dube, S., Mahlangu, T., \& Sibindi, F. (1995). Child sexual abuse in Matabeleland, Zimbabwe. Social Sciences and Medicine, 41(12), 1693-1704.

National Council for Population and Development (NCPD), (1999). Central Bureau of Statistics (CBS) (Office of the Vice President and Ministry of Planning and National Development) [Kenya], and Macro International (MI). Kenya Demographic and Health Survey 1998. Calverton, Maryland: NDPD, CBS and MI.

Okeahialam, T. (1984). Child abuse in Nigeria. Child Abuse \& Neglect, 8, 69-73.

Patel, V. \& Andrew, G. (2001). Gender, sexual abuse and risk behaviours in adolescents: a cross-sectional survey in schools in Goa. Natel Medical Journal India, 14, 263267.

Rajani, R.\& Kudrati, M. (1996). The varieties of sexual experience of the street children of Mwanza, Tanzania. In S. Zeidenstein \& K. Moore (Eds.), Learning about sexuality, a practical beginning (pp. 301-323). New York: The Population Council. 
Richter, L. M. (2003). Baby rape in South Africa. Child Abuse Review, 12(6), 392-400.

Roberts, R., O’Connor, T., Dunn, J., Golding, J., \& The ALSPAC Study Team (2004). The effects of child sexual abuse in later family life; mental health, parenting and adjustment of offspring. Child Abuse and Neglect, 28, 525-545.

Segal, U., \& Ashtekar, A. (1994). Detection of intrafamilial child abuse: children at intake at a children's observation home in India. Child Abuse \& Neglect, 18, 957967.

Shumba, A. (2004). Male sexual abuse by female and male perpetrators in Zimbabwean schools. Child Abuse Review, 13, 353-349.

Silberschmidt, M. (2001). Disempowerment of men in rural and urban East Africa: implications for male identity and sexual behaviour. World Development, 29(4), $657-671$.

Silberschmidt, M., \& Rasch, V. (2001). Adolescent girls, illegal abortions and "sugardaddies" in Dar es Salaam: vulnerable victims and active social agents. Social Science \& Medicine, 52(12), 1815-1826.

Singh, A., Yiing, W. W., \& Nurani, H. N. (1996). Prevalence of childhood sexual abuse among Malaysian paramedical students. Child Abuse \& Neglect, 20(6), 487-492.

Steel, J., Sanna, L., Hammond, B., Whipple, J., \& Cross, H. (2004). Psychological sequelae of childhood sexual abuse: abuse-related characteristics, coping strategies, and attributional style. Child Abuse and Neglect, 28, 785-801.

TAMWA (1998). A review of the Sexual Offences Special Provisions Act, 1998. Dar es Salaam: Tanzania Media Women's Association. 
Tang, C., Yik, M., Cheung, F., Choi, P. K., \& Au, K. (1996). Sexual harassment of Chinese college students. Archives of Sexual Behaviours, 25, 201-215.

Tang, C. (2002). Childhood experience of sexual abuse among Hong Kong Chinese college students. Child Abuse \& Neglect, 26, 1, 2002, 23-37.

Unicef (1999). Children in need of special protection measures, a Tanzanian study. Dar es Salaam: Unicef.

Unicef (2003). Stocktaking of child abuse and trauma materials. Dar es Salaam: Unicef. Williams, J. M. (1993). Assessing the traumatic impact of child sexual abuse: what makes it more severe. Journal of Child Sexual abuse, 2(2), 41-59. 